\title{
The atrioventricular pathway in the heart of the scaly ant-eater
}

\author{
By \\ Masaru Mori \\ The first Department of Anatomy, Faculty of Medicine, \\ Kyushu University, Fukuoka
}

There are many reports on the conduction system in the heart of mammals, and many things are known about it. If one reads Roberts's description in "Development and structure of the Cardiovascular System edited by Aldo A. Lu is a da, 1961 ", he can know many things about the conduction system in the heart of mammals. Therefore it seems to me that it is unnecessary to report the conduction system. But in reviewing the biographies of the conduction system I know that there is no report on it of the scaly ant-eater, then on present paper I report on the conduction system of the ant-eater, though it is superfluous.

\section{Material and Method}

The scaly ant-eater was caught in Formosa, and the heart was prepared in serial sections. Reconstructionmodel was made with paraffinplate.

\section{Observation}

Atrioventricular node. It is a slightly expanded club-shaped at the upper posterior end of the atriovenricular bundle, and lies in a triangle bounded by the orifice of the coronary sinus, orifice of the inferior vena cava, and the small septal cusp of the right atrioventricular valve.

The node is surrounded imperfectly with fatty tissue, and it is a rather thick sheath, and I have ascertained, by tracing the serial sections that this fatty tissue continues to the subepicardial connective tissue. In the fatty sheath there are many of nerve 
fibers from the cardiac plexus. A large nerve bundle runs touching the left side of the atrioventricular node to the ventricular septum. In the nerve fibers near the atrioventricular node there are many nerve cells. The blood-vessels in the fatty sheath come from the posterior atrial branches of the right coronary arteries.

As above-mentioned the atrioventricular node is not surrounded completely with fatty tissue, and there are no sheath on right and dorsal side. In this area the muscle fibers of the atrioventricular node pass into the usual atrial muscle fibers.

Atrioventricular bundle. It begins from the caudal end of the atrioventricular node without no distinct border between the node and the bundle; the caudal left portion of the node fines away little by little and becomes the atrioventricular bundle. The bundle runs anteriorly to the upper part of the Pars membranacea of the septum interventriculare. In this it passes downward and forward, covered by endcardium. In Pars membranacea the atrioventricular bundle is about $5.5 \mathrm{~mm}$ in length and about $5.0 \mathrm{~mm}$ in dorsoventral diameter, and about $0.25 \mathrm{~mm}$ in transverse diameter, viz. the atrioventricular bundle in the Pars membranacea is very flattened from side by side. A large nerve boundle runs along. the left side of the atrioventricular bundle. In this way the Pars membranacea consists of atrioventricular bundle, nerve bundle and endocardium.

The muscle fibers making the atrioventricular bundle in the Pars membranacea is slender and stained with eosin scarcely, therefore the microscopical figure of it differs from the figure of the muscle fibers in the atrioventricular node.

In the front and caudal end of the Pars membranacea the atrioventricular bundle is divided into a left and right limb.

The right limb is compact, a cylindrical bundle $0.2 \mathrm{~mm}$ thick, runs downward along the right surface of the septum interventriculare, locating directly under the endocardium of the right ventricle. This limb is long, and has no branch, and near the apex of the right ventricle splits into many branches which spread along the entire internal surface of the right ventricle and along the papillary muscles, and disappear in the substance of the myocardium. In reconstructionmodel I show only the stem of the limb, for it is difficult to reconstruct the endbranches of the limb.

The left limb of the bundle pierces interventricular septum and 
appears in the left ventricle a little below the Pars membranacea. It forms a flat, wide band immediately beneath the endocardium, and passes along the septal wall toward the apex and divided into two main branches on the border between the upper and middle thirds of the septum; then it separates, as in the right ventricle into numerous, anastomosing thin threads which are lost to view in the myocardium.

The right and left limb are surrounded with connective tissue, and separated from the myocardial muscle.

Histological. The muscle fibers of the atrioventricular are alike in some degree to the typical Purkinje's fiber. In the histological figure of the conduction system in the Pars membranacea of the septum interventriculare there is a large gulf between the typical Purkinje's fiber.

The histological figure of the stem of the right limb differs from the myocardial fiber, and it has almost same structure as the Purkinje's fiber. In the left limb I could not found typical Purkinje's fiber, the histological figure of it almost same as the myocardial muscle.

\section{Summary}

The author showed the atrioventricular pathway in the heart of the scaly ant-eater by reconstructionmodel, and the author did not take up the problem of the sinoatrial node and the connection between the sinoatrial and the atrioventricular node.

\section{Reference}

Aldo A. Luisada, Development and structure of the cardiovascular system. McGraw-Hill, New York. 1961. 


\section{Explanation of figures}

1. Immediate below of the atrioventricular system.

2. Conduction system in the Pars membranacea of septum interventriculare.

3.4. Conduction system divides here.

5. Right and left limb are separated.

6. Position of the right and left limb in the upper portion of the muscular interventaicular septum.

7. Atrioventricular node. It is enclosed with dotted line.

8. Histological figure of the conduction system in the Pars membranacea of septum interventriculare.

9. Right limb. It is enclosed with dotted line.

10. Left limb. It is showed with arrow.

$R$; right ventricle. $L$; left ventricle. 
Plate I

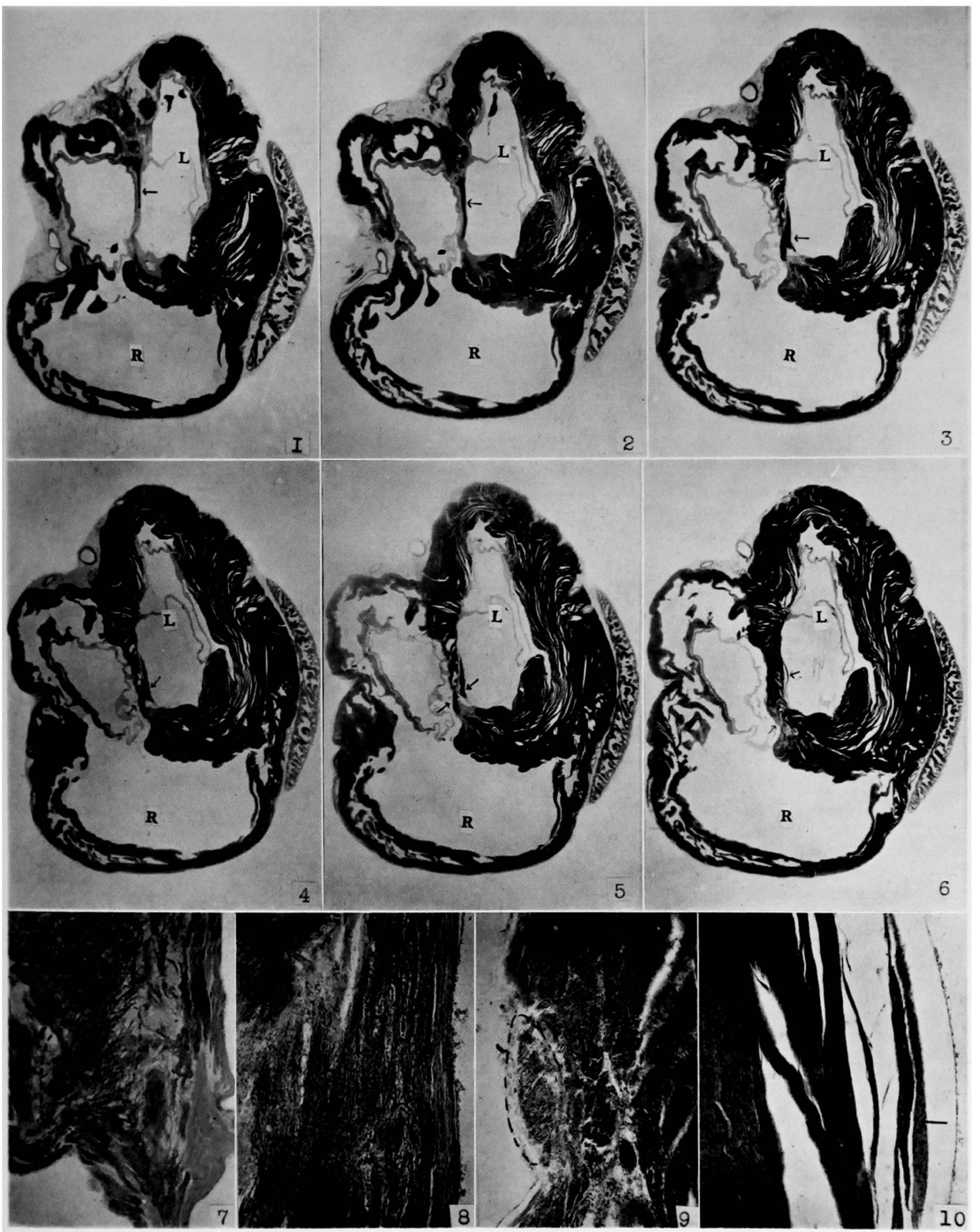

M. Mori 
Plate II

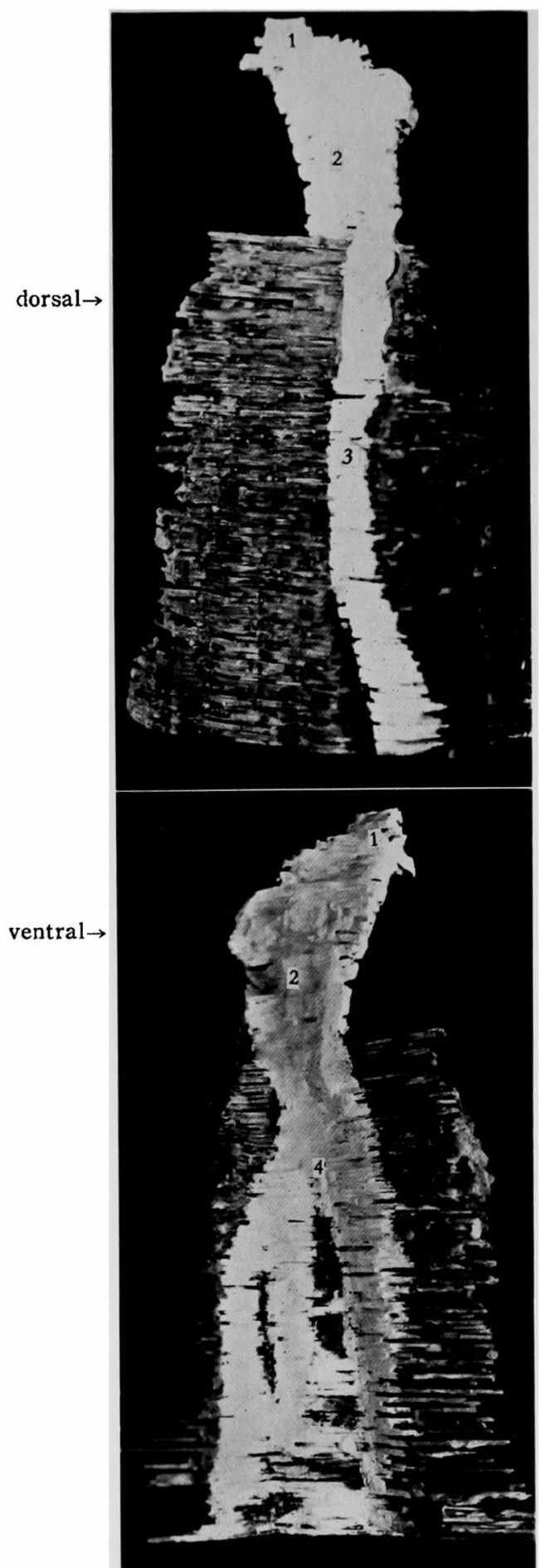

Above; right ventricular surface. Below; left ventricular surface. $\leftarrow$ ventral

$\leftarrow$ dorsal

Reconstruction of conduction system.

apper; right side of the interventricular septum.

lower; left side of the interventricular septum.

1. atrioventricular node.

2. conduction system in membranous septum.

3. right limb.

4. left limb. 